\title{
PHARMACOKINETICS AND PHARMACODYNAMICS EVALUATION OF PREPARED ZINC ASPIRIN SUPPOSITORIES
}

Fergany A. Mohamed ${ }^{1}$, Saida A. Aly ${ }^{2}$ and Hamdy M. Abdel-Rahman ${ }^{3}$

${ }^{1}$ Department of Pharmaceutics, Faculty of Pharmacy, Assiut University, Assiut, Egypt

${ }^{2}$ Department of Pharmacology, Faculty of Medicine, Assiut University, Assiut, Egypt

${ }^{3}$ Department of Pharmaceutical Medicinal Chemistry, Faculty of Pharmacy, Assiut University, Assiut Egypt

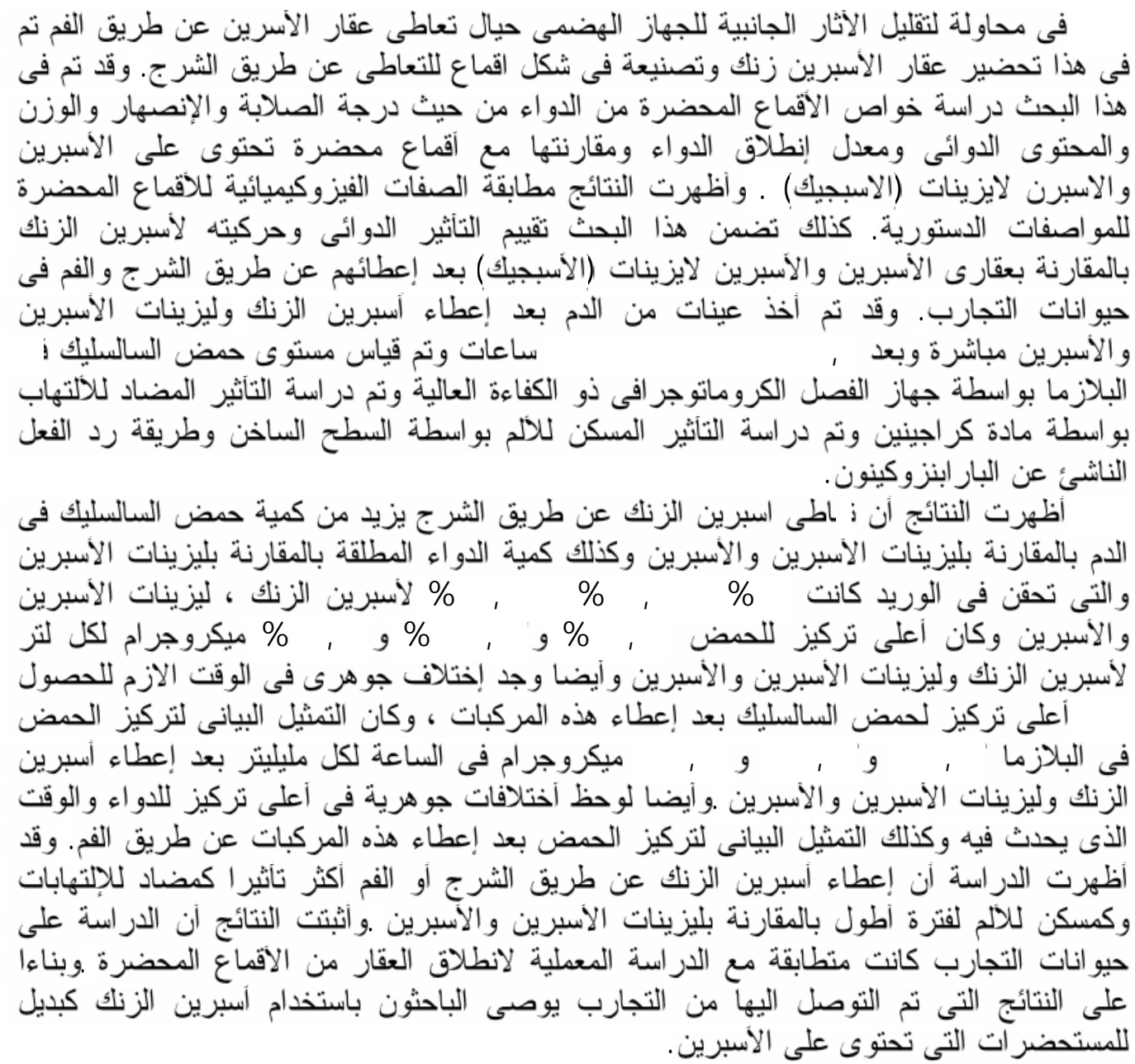

In an attempt to reduce the gastrointestinal side effects of aspirin, zinc aspirin complex was prepared and formulated into suppositories. The prepared suppositories were evaluated invitro for their hardness, melting range, uniformity of weight and drug content and in-vivo drug release.

The pharmacokinetic and pharmacodynamic properties of zinc aspirin were evaluated in comparison with that of aspirin and aspirin lysinate (aspegic) following rectal and oral administration in experimental animals. Blood samples were collected at different time intervals after adminstration of drugs under evaluation. Salicylic acid (main metabolite of aspirin) was determined in plasma by using high performance liquid chromatography (HPLC). The antiinflammatory activity was studied in albino rats using carrageenan oedema model; and the analgesic activity was studied using hot plate and writhing methods.

The results revealed that following rectal administration, the bioavailability of zinc aspirin was significantly $(P<0.05)$ greater than that of aspirin and aspirin Lysinate. The absolute 
bioavailabilities were 94, 88.89 and 83.63 for zinc aspirin; aspirin lysinate and aspirin respectively. The peak plasma concentration $\left(C_{\max }\right)$ were $54.51 \pm 88,50.27 \pm 1.68$ and $48.09 \pm 1.15$ $u g l^{-1}$ for zinc aspirin, aspirin lysinate and aspirin, respectively. There was significant difference in the $t_{\max }$. The area under the plasma concentration-time curve (AUC) values were $148.93 \pm 2.79,140.83 \pm 2.3$ and $132.49 \pm 3.56 \mathrm{ug} . \mathrm{h} / \mathrm{ml}$ for zinc aspirin, aspirin lysinate and aspirin, respectively. There were significant differences in the $C_{\max }, t_{\max }$ and AUC following oral administration. The anti-inflammatory and analgesic studies revealed that zinc aspirin administered rectally or orally was more effective as anti-inflammatory and analgesic. The invivo studies were correlated with the in-vitro release studies of aspirin from the prepared suppositories.

Based on the obtained results, the authors recommend the possible use of zinc aspirin as a substitute of aspirin containing products.

\section{INTRODUCTION}

The principal limiting side effect of acidic non-steroidal anti-inflammatory drugs (NSAIDs) is the gastrointestinal inflammations (erosion, ulceration and bleeding). Gastrointestinal inflammations and bleeding in case of aspirin, is mainly due to its local effect. $^{1-3}$ Aspirin-induced blood loss and gastrointestinal ulcerations may be reduced by its administration as a modified release preparations rather than as conventional oral preparations. ${ }^{4}$

Zinc is known to possess anti-ulcer and anti-inflammatory properties. Zinc sulphate is given internally in doses up to $220 \mathrm{mg}$ (equivalent to $50 \mathrm{mg}$ zinc) to assist healing of human gastric ulcers. ${ }^{5,6}$ Laboratory animal investigations have also demonstrated the protective effect of zinc compounds against experimental ulcers, including gastric ulceration induced by electrical vagal stimulation, ${ }^{7}$ restraint stress, ${ }^{8,9}$ pylorus occlusion, ${ }^{10}$ ethanol ${ }^{11}$ and acetic acid. ${ }^{12}$ Zinc reduces the inflammatory processes through different mechanisms which has been confirmed by the use of zinc sulphate in rheumatoid arthritis and in psoriatic arthritis. ${ }^{13}$

Between the reported advantages of zinc aspirin complex are: a) the free carboxyl group of aspirin will be masked; b) the ulcergenicity of aspirin will be reduced; c) zinc may add to the anti-inflammatory of aspirin; d) gastrointestinal absorption of aspirin as well as zinc may be enhanced from the complex form; and e) zinc will be present in a better tolerated form. ${ }^{14}$

Zinc based anti-irritant creams (US Patent No. $5,985,918)$ and indancarboxylic acid zinc salts (US Patent No. 4,440,691) has been reported. The physico-chemical and biological properties of zinc-aspirin complex have been studied. $^{14}$ A paucity of information are available about the pharmacokinetics and bioavailability of zinc asprin in healthy volunteers. Zinc aspirin and aspirin were reported as bioequivalent, with the former being easier to absorb. ${ }^{15}$

The aim of the present study was to investigate the pharmacokinetics and pharmacodynamic properties of zinc aspirin complex following rectal and oral administration. Those pharmacokinetics and pharmacodynamic properties of zinc aspirin were compared with those of asprin and asprin lysinate as standred drugs.

\section{MATERIAL AND METHODS}

\section{Materials}

Aspirin (The United Pharmaceutical Manufacturing Co., Amman, Jordan). Suppocire AM (Gattefosse, Saint-priest, France). P-benzoquinone (Prolabo Co.). Carrageenan from Sigma Ltd.

\section{Commercial products}

Aspegic ${ }^{\circledR}$ Injectable $0.5 \mathrm{~g}$, containing 500 $\mathrm{mg}$ aspirin (acetylsalicylic acid) powder in the form of aspirin lysinate complex (Laboratories Synthelabo, Batch No. 1800202, France).

All other reagents and chemicals were of analytical grade.

\section{Methods}

Melting points were determined with an electrothermal apparatus (Stuart Scientific, England) and are uncorrected. Thin layer chromatography (TLC) was performed on 
precoated Merck silica gel $60 \mathrm{~F}_{254}$ sheets. IR spectra were reported on a Shimadzu-470 infrared spectrophotometer using potassium bromide pellets. ${ }^{1} \mathrm{H}$ NMR spectra were recorded on a Varian EM-360L (60 MHz) Spectrometer. Chemical shifts are given in $(\delta$ $\mathrm{ppm}$ ) relative to TMS as an internal standard.

Analytical reversed-phase HPLC was performed by Knauer pump 64, Germany, a variable-wave length Knauer detector utilizing a reverse-phase C18 column (Eurosphere 80 RP-18, 25X0.5 cm i.d.). chromatographic separations were achieved using a mobile phase of acetonitrile and water peaks were detected spectrophotometrically at $237 \mathrm{~nm}$ and retention time $\left(\mathrm{R}_{\mathrm{t}}\right)$ was recorded in minutes.

\section{Preparation of zinc-aspirin complex}

Acetylsalicylic acid (9 g, 0.05 mole) was dissolved in a solution of sodium bicarbonate (4.2 g, 0.05 mole) in water $(60 \mathrm{ml})$. The solution was filtered and slowly added to it with constant stirring a solution of zinc sulphate heptahydrate (7.2 g, 0.025 mole) in water $(20 \mathrm{ml})$. Turbidity appeared which on keeping at $10-15{ }^{\circ} \mathrm{C}$ led to the formation of white crystals. The crystals were filtered, washed with cold water and dried under vacuum to constant weight to give the titled compound (7.51 g, $70 \%$ ) m.p $116-118^{\circ}$ as reported. ${ }^{14,15}$

\section{Preparation of suppositories}

Infantile size ( $1 \mathrm{~g})$ zinc aspirin, aspirin lysinate and aspirin suppositories were prepared by melting method, ${ }^{16,17}$ using Suppocire AM as suppository base. An amount of zinc aspirin (equivalent to $50 \mathrm{mg}$ aspirin), aspirin lysinate (equivalent to $50 \mathrm{mg}$ aspirin) or aspirin $(50 \mathrm{mg}$ ) was accurately weighed and incorporated to the melted base. The mixture was poured into a metal mold (12 cavities) and allowed to cool at room temperature. All suppositories were stored at room temperature for 48 hours before use.

\section{Physicochemical properties Hardness}

Hardness was tested by Erweka hardness tester (Apparatebaa $\mathrm{GmbH}$, type SBT, Germany). Data reported are the mean (CV\%) of ten suppositories.

\section{Melting range}

The melting range was determined by recording the initial and final melting points $\left({ }^{\circ} \mathrm{C}\right)$ by using the U-Tube method.

\section{Uniformity of weight}

Weight variation was determined by weighting ten suppositories and the percentage deviation (CV\%) from the mean was determined according to USP. ${ }^{18}$

\section{Uniformity of drug content}

The aspirin content in each of ten suppositories was determined according to USP. ${ }^{18}$ Each suppository was dissolved in chloroform in an appropriate volumetric flask. An aliquot was diluted to $100 \mathrm{ml}$ with $1 \%$ acetic acid in chloroform to give a concentration similar to the standard. The absorbance of both the standard and the sample was measured at $280 \mathrm{~nm}$. (Shimadzu, UV/Vis) and the mean percent aspirin $(\mathrm{CV} \%)$ was determined by Kirchhoefer et al. ${ }^{19}$

\section{In-vitro drug release study}

The release of the drug from the prepared zinc aspirin, aspirin lysinate and aspirin suppositories was studied by adopting a dialysis method. ${ }^{19-21}$ In this method, two open ended glass tubes of $1.8 \mathrm{~cm}$ internal diameter were selected and cellophane memberanes (30/32, Najax, Paris) were tied by a rubber band across one end of each tube. To each of the prepared dialysis tubes (donor compartment), $2 \mathrm{ml}$ of phosphate buffer ( $\mathrm{pH}$ 7.4) were added and each tube was suspended in a $400 \mathrm{ml}$ beaker containing $200 \mathrm{ml}$ phosphate buffer pH 7.4 (receptor compartment). The whole system was then placed in a thermostatically controlled water bath (GFL, type 1085 , Fed Rep, Germany) seted at $37^{\circ}$ and $50 \mathrm{rpm}$. Four tubes were used for each suppository formulation. When equilibrium temperature was attained, one suppository was placed in each of the dialysis tubes (donor compartment). At time intervals of $0.5,1,2,3$, 4 and 5 hours, $5 \mathrm{ml}$ samples were withdrawn form the beaker (receptor compartment) and replaced with equal volume of fresh buffer at the same temperature. The drug content of the withdrawn samples was determined spectrophtometrically at $275 \mathrm{~nm} .^{19-21}$ 


\section{Kinetics of release}

To determine the mechanism of release of aspirin form the prepared suppositories, the data were fitted to various kinetic equations. ${ }^{23,24}$

\section{Bioavailability Studies}

The bioavailability of zinc aspirin, aspirin lysinate and aspirin measured as salicylic acid, after rectal and oral administration was performed in rabbits. Male and female rabbits $(1.52 \mathrm{~kg})$ were randomly divided into 7 groups of 6 animals each. The dose level of zinc aspirin, aspirin lysinate and aspinin 25 $\mathrm{mg} \cdot \mathrm{kg}^{-1}{ }^{24,25}$ Blood $(2 \mathrm{ml}$ ) were withdrawn from the eye vein into heparin tubes before administration (zero time) and at 0.5, 1, 2, 3, 4, and 5 hours following drug administration. Plasma was immediately separated by centrifugation and stored at $4^{\circ}$. The concentration of salicylic acid was determined by using high performance liquid chromatography (HPLC). ${ }^{25}$

\section{Pharmacokinetic and parameters and statistical analysis}

The pharmacokinetic parameters such the maximum plasma concentration $\left(\mathrm{C}_{\max }\right)$, time to reach this maximum concentration $\left(\mathrm{t}_{\max }\right)$ and area under the plasma concentration (AUC) were calculated from the plasma concentrationtime curves. ${ }^{26,27}$ The relative bioavailability $\left(\mathrm{F}_{\mathrm{r}}\right)$ was determined by dividing the $\mathrm{AUC}_{0-5 \mathrm{~h}}$ of zinc aspirin, aspirin lysinate and aspirin by that of aspirin orally. The absolute bioavailability $\left(\mathrm{F}_{\mathrm{A}}\right)$ also was determined by dividing the $\mathrm{AUC}_{0-5 \mathrm{~h}}$ rectally and orally administration of zinc aspirin and aspirin lysinate and aspirin by that of aspirin lysinate intravenously. The analysis of variance one way ANOVA was utilized to determine the differences in the $\mathrm{C}_{\max }$ and $\mathrm{AUC}_{0-5 \mathrm{~h}}$.

\section{Statistical studies}

Statistical tests were performed using Prism 3 software (Graphad USA). Multiple groups at the same time points were compared using ANOVA one way method followed by Dunnett's multiple comparison test The difference were regarded as significant when $\mathrm{P}<0.05$ and highly significant when $\mathrm{P}<0.01$.

\section{Pharmacodynamic studies}

\section{A- Evaluation of the analgesic activity}

The analgesic activity of zinc aspirin, aspirin lysinate and aspirin was studied in mice using two different methods:

\section{I- Hot plate method}

According to the method described by Lewis and Gebhart ${ }^{28}$ the time taken by the mouse to lick its feet or to jump within a plexiglass cylinder placed on a hot plate surface $\left(55^{\circ}\right)$ was determined. This reaction time was taken as the end point and the increase in hot plate latency was taken as a measure of the analgesic activity of these drugs. Rectal and oral administration of zinc aspirin, aspirin lysinate and aspirin to different groups of adult albino mice (20-28 $\mathrm{g}$ ) in a dose equal to $25 \mathrm{mg} / \mathrm{kg}$ of the drug. The analgesic activity was evaluated at 1, 2, 3, 4 and 5 hours after administration. One group of mice was used for each time interval action. Control animals were treated orally with $1 \mathrm{ml}$ of distilled water and rectally with suppository base.

\section{II- Writhing method}

The analgesic activity of zinc aspirin and comparative studies with aspirin lysinate and aspirin was also studied using P-benzoquinone writhing method in mice. ${ }^{29}$ Before carrying out the experiments, a sensitivity test was done to determine the sensitivity of mice to Pbenzoquinone. In this test, animals were given an intraperitoneal injection of $0.25 \mathrm{ml}$ of $0.02 \%$ solution of p-benzoquinone in water. The animals were observed for writhing during a period of one hour. Only animals which responded to $\mathrm{p}$-benzoquinone by writhing were used in the main experiments, not less than 48 hours later.

Zinc aspirin, aspirin lysinate and aspirin were orally and rectally administered to different groups of equal to $25 \mathrm{mg} / \mathrm{kg}$ of each drug and allowed to act for different time intervals 1, 2, 3, 4 and 5 hours. One group of mice was used for each time interval. Control animals were treated with $1 \mathrm{ml}$ of distilled water and base of suppositories. Following the specified period of time, the animals were intra-peritoneal injected with $0.25 \mathrm{ml}$ of $0.02 \%$ solution p-benzoquinone of water. The animals 
were observed for writhing during a period of one hour. The percentage protection against induced writhing was determined.

\section{B- Evaluation of the anti-inflammatory activity}

Anti-inflammatory effect of each of zinc aspirin, aspirin lysinate and aspirin was tested as described by the method of Winter et al. ${ }^{30}$ This method is based on induction of inflammation in the hind paw on the rats by subcutaneous injection of $50 \mathrm{ul}$ of $1 \%$ carrageenan sodium gel into the plantar surface of the right hind paw. After 4 hours the thickness of rat paw edema was measured using skin caliber to detect the extent of inflammatory edema. Drugs were orally and rectally administered into different groups of rats in a dose of $25 \mathrm{mg} \cdot \mathrm{kg}^{-1}$ for zinc aspirin, aspirin lysinate and aspirin. The antiinflammatory effect was determined by measuring the paw's thickness after 1, 2, 3, 4 and 5 hours following drug administration. One group of rats was used for each time interval.

Control animals were treated similarly after administration of $2 \mathrm{ml}$ distilled water for orally and the base of suppository for rectally.

\section{RESULTS AND DISCUSSION}

\section{Characterization of zinc-aspirin complex}

The reaction between sodium salt of aspirin (acetyl salicylic acid) and zinc salts results in the formation of the zinc aspirin complex as shown in scheme 1 . The complex was identified as bis(acetylsalicylato)-diaquozinc(II)-complex [Zn(acetylsalicylate $\left.)_{2}\left(\mathrm{H}_{2} \mathrm{O}\right)_{2}\right]$ based on the preliminary examinations by IR, NMR, and DSC and comparing the results obtained with that reported. ${ }^{14,31,32}$ The IR study (Table 4) showed hat the spectrum of zinc acetylsalicyclic acid complex does not exhibit the band representing $\mathrm{CO}$ in the $\mathrm{COOH}$ group at around $1690 \mathrm{~cm}^{-1}$. The absorption of the carboxyl group is shifted in the direction to longer wave length indicating that it is strongly involved in complexation with zinc. Also the ${ }^{1} \mathrm{H}-\mathrm{NMR}$ spectrum of the zinc-aspirin complex confirmed the structure by showing the disappearance of proton of the carboxyl group at $\delta 12.0-12.1$<smiles>CC(=O)Oc1ccccc1C(=O)O</smiles>

acetylsalicylic acid<smiles>NC(=O)O[Na]</smiles><smiles>CC(=O)Oc1ccccc1C(=O)[O-]</smiles>

$\mathrm{Zn}$ (acetylsalicylate $)_{2}\left(\mathrm{H}_{2} \mathrm{O}\right)_{2}$

Scheme 1: Synthesis of zinc-aspirin complex

\section{In-vitro studies}

The physicochemical characteristics of the prepared zinc aspirin, aspirin lysinate (Aspegic) and aspirin suppositories are shown in Table 1. The prepared suppositories showed acceptable hardness, melting range, uniformity of weight and drug content (Table 1).

The release profiles of aspirin from the prepared aspirin lysinate and aspirin suppositories in phosphate buffer $(\mathrm{pH} 7.4)$ are shown in Fig.1. The results indicated that the release of aspirin from zinc aspirin and aspirin lysinate suppositories was found to be higher than aspirin suppositories. This could be attributed to the fact that zinc aspirin and aspirin lysinate are water soluble while aspirin is water insoluble.

Table 2 summarizes the release kinetics of aspirin from the prepared suppositories. The selection of the release mechanism was based on the higher value of the linear correlation coefficient (r). However, $r$ values of more than 0.95 ( $r>0.95)$ were obtained for all the tested kinetic equations (zero order, first order, second order and Higuchi equation), and therefore, it was difficult to determine the mechanism of drug release through the data in Table 2. The release data was then fitted to the diffusion equation of Ritger and Peppas, ${ }^{22}$ (Table 3). 
Table 1: Physicochemical characteristics, mean (CV\%), of the prepared zinc aspirin, aspirin lysinate (Aspegic) and aspirin suppositories.

\begin{tabular}{|l|c|c|c|}
\hline \multicolumn{1}{|c|}{$\begin{array}{c}\text { Physical } \\
\text { characteristics }\end{array}$} & Zinc Aspirin & Aspirin lysinate & Aspirin \\
\hline Hardness $(\mathrm{kg})$ & $3.95(5.84)$ & $5.55(7.08)$ & $2.80(4.40)$ \\
\hline Melting range $\left({ }^{\circ}\right)$ & $35(2.5)-37.5(3.5)$ & $34.5(3.6)-37.5(3.5)$ & $35.8(3.5)-37.4(3.9)$ \\
\hline Weight $(\mathrm{gm})$ & $1.12(5.4)$ & $1.11(5.6)$ & $1.16(3.4)$ \\
\hline Drug content $(\%)$ & $98.50(3.85)$ & $97.50(3.96)$ & $98.30(2.37)$ \\
\hline
\end{tabular}

Table 2: Kinetic parameters obtained by fitting the release data of zinc aspirin, aspirin lysinate and aspirin suppositories.

\begin{tabular}{|c|c|c|c|c|}
\hline Mechanism & $\begin{array}{c}\text { Kinetic } \\
\text { parameters* }\end{array}$ & Zinc Aspirin & Aspirin lysinate & Aspirin \\
\hline \multirow{4}{*}{ Zero-order } & $\mathrm{A}$ & 16.35 & 21.33 & 3.86 \\
\hline & $\mathrm{B}$ & 11.96 & 10.33 & 11.18 \\
\hline & $\mathrm{K}$ & 11.96 & 10.33 & 11.18 \\
\hline & $\mathrm{r}$ & 0.967 & 0.986 & 0.990 \\
\hline \multirow{4}{*}{ First-order } & $\mathrm{A}$ & 2.16 & 2.11 & 2.05 \\
\hline & $\mathrm{B}$ & -0.241 & -0.207 & -0.106 \\
\hline & $\mathrm{K}$ & 0.557 & 0.375 & 0.245 \\
\hline & $\mathrm{r}$ & 0.944 & 0.913 & 0.989 \\
\hline \multirow{4}{*}{ Second-order } & $\mathrm{A}$ & 0.006 & 0.010 & 0.003 \\
\hline & $\mathrm{B}$ & 0.008 & 0.005 & 0.006 \\
\hline & $\mathrm{K}$ & 0.008 & 0.005 & 0.006 \\
\hline & $\mathrm{r}$ & 0.956 & 0.947 & 0.949 \\
\hline \multirow{4}{*}{$\begin{array}{l}\text { Higuchi- } \\
\text { equation }\end{array}$} & $\mathrm{A}$ & -12.01 & -1.72 & -21.17 \\
\hline & $\mathrm{B}$ & 41.38 & 35.00 & 37.91 \\
\hline & $\mathrm{K}$ & 41.38 & 35.00 & 37.91 \\
\hline & $\mathrm{r}$ & 0.995 & 0.988 & 0.990 \\
\hline
\end{tabular}

*A= intercept, $\mathrm{B}=$ slope, $\mathrm{K}=$ specific rate constant, $\mathrm{r}=$ linear correlation coefficient

Table 3: Determination coefficients $\left(r^{2}\right)$, kinetic release constants and diffusion exponents (n) obtained by fitting the release data of zinc aspirin, aspirin lysinate and aspirin suppositories to the simple diffusional equation.

\begin{tabular}{||c|c|c|c|}
\hline \multicolumn{1}{|c|}{$\begin{array}{c}\text { Suppository } \\
\text { Formulations }\end{array}$} & $\mathrm{r}^{2}$ & $\mathrm{~K}\left(\mathrm{~h}^{-\mathrm{n}}\right)$ & $\mathrm{n}^{(*)}$ \\
\hline Zinc Aspirin & 0.990 & 25.70 & 0.723 \\
\hline Aspirin lysinate & 0.980 & 33.11 & 0.540 \\
\hline Aspirin & 0.992 & 14.66 & 0.983 \\
\hline
\end{tabular}




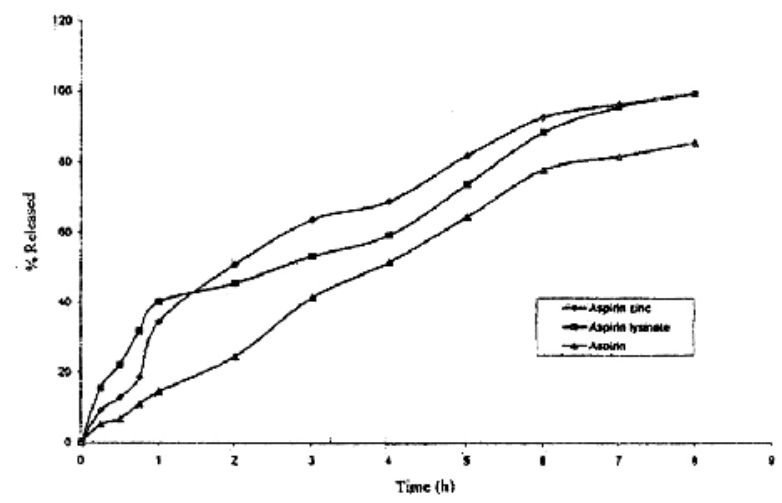

Fig. 1: Release profiles of drug from rectal suppositories prepared with aspirin zinc, aspirin lysinate and aspirin.

Diffusional exponents, $\mathrm{n}$ values of $0.723,0.540$ and 0.983 were obtained for zinc aspirin, aspirin lysinate and aspirin suppositories respectively (Table 3 ). The obtained $n$ value of 0.723 indicate a non-Fickian transport mechanism of the drug from the prepared zinc aspirin suppositories. This characterizes a mixture of diffusional and relaxation release mechanisms or a so called anomalous diffusion. ${ }^{22,33}$ The $n$ value of 0.540 obtained for aspirin lysinate suppositories is also an indicative of a non-Fikian transport mechanism, but however, since this value, 0.540 , approximates 0.5 , so, the release of the drug from this formulation is best described by the Fickian/diffusion mechanism. On the other hand, the $n$ value of 0.983 obtained for aspirin suppositories is also an indicative of a nonFikian transport mechanism, but however, since this value, 0.983 , approximates 2 , so, the release of the drug form this formulation is best described by the zero-order. ${ }^{22}$ These results are similar to those obtained by Abd Elbary and Whitworth, ${ }^{21}$ who reported zero-order mechanism for the release of aspirin from an oleaginous semisynthetic suppository base.

\section{Bioavailability studies and pharmacokinetic parameters}

Figures 2 and 3 show the plasma concentration-time profiles of salicylic acid following rectal and oral administration of zinc aspirin, aspirin lysinate and aspirin, (25 $\left.\mathrm{mg} \cdot \mathrm{kg}^{-1}\right)$. These data clearly indicate that systemic bioavailability of salicylic acid after rectal administration of the previous drug was higher than that obtained after an equivalent oral dose. These findings are consistent with the finding of pervious investigations, ${ }^{34,35}$ who reported that serum salicylic acid level from rectally-infused doses was higher than form oral dose.

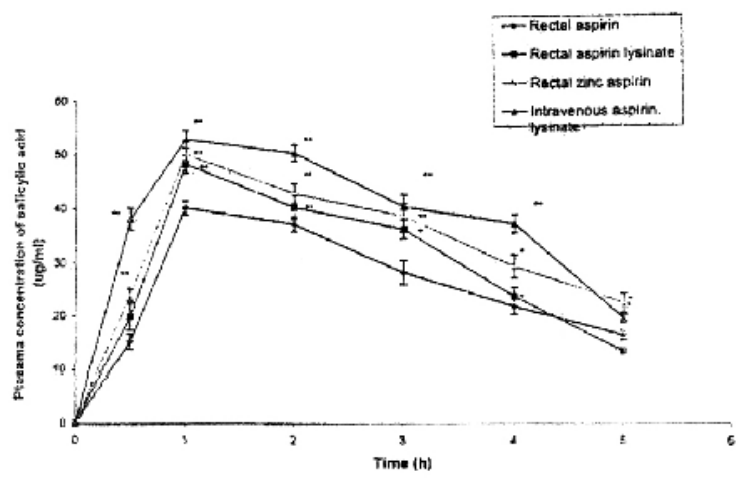

Fig. 2: Plasma concentration-time profiles of salicylic acid after rectal administration of zinc aspirin, aspirin lysinate, aspirin and I.V. administration of aspirin lysinate (25 $\mathrm{mg} / \mathrm{kg}$ ).

* Significant result $(\mathrm{P}<0.05)$.

** Significant result $(\mathrm{P}<0.01)$.

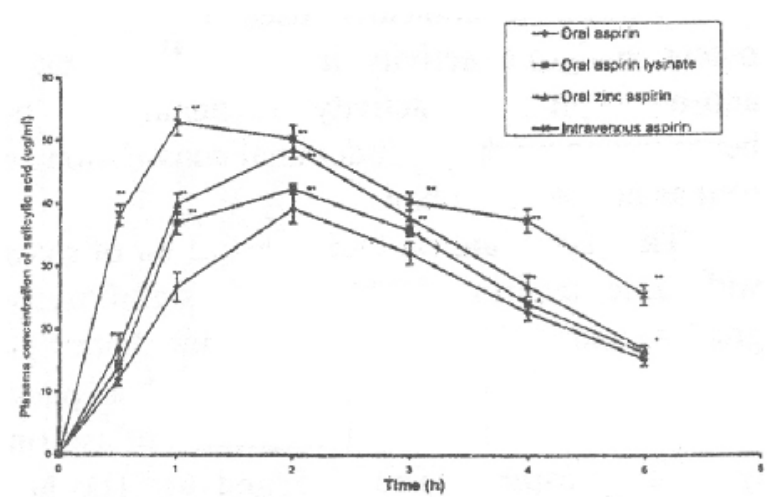

Fig. 3: Plasma concentration-time profiles of salicylic acid after oral administration of zinc aspirin, aspirin lysinate, aspirin and I.V. administration of aspirin lysinate (25 $\mathrm{mg} / \mathrm{kg})$.

* Significant result $(\mathrm{P}<0.05)$.

** Significant result $(\mathrm{P}<0.01)$

The relative high plasma levels of salicylic acid observed in rectally treated rabbits are probably a reflection of partial avoidance of the first pass metabolism. ${ }^{36,37}$ Only approximately 50 to $70 \%$ of the dose reaches the systemic circulation as unchanged drug. ${ }^{38,39}$ In clinical pharmacological studies osmotic rectal infusion systems proved to be interesting alternative for intravenous infusion. ${ }^{40}$ 
A higher plasma concentration of salicylic acid was observed with zinc aspirin than that aspirin lysinate and aspirin. These data clearly indicate that aspirin is more rapidly absorbed from zinc aspirin as compared to aspirin lysinate and aspirin. This could be attributed to the increased solubility and dissolution of aspirin in the presence of zinc. ${ }^{41}$

Table 4 summarizes the pharmacokinetic parameters of salicylic acid following rectal and oral administration of zinc aspirin, aspirin lysinate and aspirin. The use of zinc aspirin significantly $(\mathrm{P}<0.05)$ increased the $\mathrm{C}_{\max }$ and decreased the $\mathrm{t}_{\max }$ as compared to aspirin lysinate and aspirin (Table 4).

The AUC was also significantly $(\mathrm{P}<0.01)$ indicating more complete absorption of aspirin from zinc aspirin (Table 4). The absolute and relative bioavailability of salicylic acid after zinc aspirin administration was higher than aspirin lysinate and aspirin (Table 4).

\section{Analgesic activity}

Aspirin, a clinically used NSAID with potent analgesic activity in man, ${ }^{42,43}$ exhibited anti-nociceptive activity against bbenzoquinone-induced abdominal constriction as well as hot plate method.

The rectal and oral administration of mice with zinc aspirin resulted in a significantly greater anti-nociceptive effect in both $\mathrm{p}$ benzoquinone-induced writhing and hot plate methode than following administration of aspirin lysinate or aspirin (Tables 5 and 6). The hot plate latency was found to increase when zinc aspirin was given rectally. Control mice were found to have a reaction time rangion form 6.6 to 7.0 second at different time intervals. The maximum reaction time of zinc aspirin, aspirin lysinate and aspirin revealed after 1 hour and were 25.8 $\pm 6,14.8 \pm 47$ and $12.17 \pm 79$ second respectively (Fig. 5). While the oral administration of zinc aspirin increased significantly the rection time to reach the maximum after $2 \mathrm{hr}$ (17.6 \pm 11 second), and effectively continued for 5 hrs $(8.4 \pm 0.53$ second compared with control group (Table 6).

Data in Tables 7 and 8 represent the percentage protection against PBQ-induced writhing. The results revealed that rectal and oral administration of zinc aspirin has the ability to partially protect the mice from chemical pain induced by PBQ for $5 \mathrm{hr}$ as well as aspirin lysinate and aspirin, while the control animals did not show any protection against the writhing. Mice given zinc aspirin; aspirin lysinate and aspirin rectally showed maximal inhibition of writhing by percentage of 90,80 and 60 respectively after $1 \mathrm{hr}$. While the oral administration of zinc aspirin, aspirin lysinate and aspirin produce maximal inhibition of writhing by percentage of 80,70 and 60 after $2 \mathrm{hr}$. This increasing in the analgesic activity of zinc aspirin is an indication of the synergistic effect when aspirin and zinc are mixed together in one combination.

The mechanism of the synergistic antinociceptive effect of zinc aspirin may be attributed to zinc inhibits prostaglandin biosynthesis, ${ }^{44}$ and enhance gastrointestinal absorption of aspirin as well as zinc from the complex form. ${ }^{41}$ Whilst it is already well established that NSAIDs such as aspirin exerts its analgesic effect through inhibition of prostaglandin synthesis. ${ }^{45,46}$

\section{Anti-inflammatory activity}

Figures 4 and 5 presents the antiinflammatory activity of zinc aspirin, aspirin lysinate and aspirin at different time interval against inflammation induced by carageenan in rats. It is evident from figures 4 and 5 that, the mean of paw oedema thickness of control animals ranged from 76 to $83 \mathrm{~mm}$. The development of oedema following the injection of carrageenan (1-5 hours) has been correlated with the elevation production of prostaglandin. ${ }^{47}$ It has been also attributed to the induction of inducible cyclo-oxygenase (COX-2) in hind paw. ${ }^{48}$ Local neutrophil infiltration and activation also contribute to this inflammatory response. ${ }^{49}$ By producing among other mediators, oxygen-derived free radicals such as superoxide anion $\left(\mathrm{O}_{2}^{-}\right)$and hydroxyl radicals. ${ }^{50}$

The anti-inflammatory activity can be measured the thickness of the rat paw using skin caliber to detect the extent of inflammatory edema. Zinc aspirin produced marked and highly significant decrease in the rat's paw oedema at 1, 2, 3, 4 and 5 hours after administration (Figures 4 and 5). The maximal anti-inflammatory effect of zinc aspirin appeared after 1 and 2 hours after rectal and oral administration respectively. 
Table 4: Pharmacokinetic parameters of serum salicylic acid after oral and rectal administration of zinc aspirin aspirin lysinate and aspirin, and intravenous administration of aspirin lysinate $\left(25 \mathrm{mg} / \mathrm{kg}^{-1}\right)$.

\begin{tabular}{|c|c|c|c|c|c|c|c|}
\hline \multicolumn{4}{|c|}{ Rectally } & \multicolumn{3}{|c|}{ Orally } & Intravenously \\
\hline Parameter & Zinc Aspirin & Aspirin Lysinate & Aspirin & Zinc Aspirin & Aspirin Lysinate & Aspirin & Aspirin lysinate \\
\hline $\mathrm{C}_{\max }\left(\mathrm{ugL}^{-1}\right)$ & $54.51^{* *++} \pm .88$ & $50.27^{* *} \pm 1.68$ & $48.09^{*} \pm 1.15$ & $49.68^{*} \pm 2.56$ & $44.87 \pm 1.64$ & $40.05 \pm 2.57$ & $58.67^{* *++} \pm 1.53$ \\
\hline $\mathrm{t}_{\max }(\mathrm{h})$ & $1.16^{* *+} \pm .17$ & $1.32^{* *} \pm .20$ & $1.56^{*} \pm 31$ & $1.84 *^{*} \pm 24$ & $2.17 \pm .21$ & $2.58 \pm 17$ & $1.1^{* *++} \pm .22$ \\
\hline $\mathrm{AUC}\left(\operatorname{ugL}^{-1-h}\right)$ & $148.93^{* *++} \pm 2.79$ & $140.83^{*} \pm 2.3$ & $132.49 \pm 3.56$ & $139.91^{* *} \pm 3.14$ & $130.54 \pm 1.87$ & $127.71 \pm 2.14$ & $158.43^{* *++} \pm 3.92$ \\
\hline $\mathrm{F}_{\mathrm{A}}(\%)$ & 94.0 & 88.89 & 83.63 & 88.31 & 82.39 & 80.61 & - \\
\hline $\mathrm{F}_{\mathrm{R}}$ & 1.16 & 1.07 & 1.04 & 1.09 & 1.02 & - & 1.24 \\
\hline
\end{tabular}

Values represent the means \pm SE from 6 animals in each group.

* Significant result at $(\mathrm{P}<0.05)$ compared with the orally aspirin treated group

** Significant result at $(\mathrm{P}<0.01)$ compared with the orally aspirin treated group.

+ Significant result at $\mathrm{P}(0.05)$ compared with the rectally aspirin treated group.

++ Significant result $\mathrm{P}(0.01)$ compared with the rectally aspirin treated group. 
Table 5: Analgesic activity of zinc aspirin, aspirin lysinate and aspirin, as measured by hot plate method in mice.

\begin{tabular}{|c|c|c|c|c|}
\hline Time after rectal & \multicolumn{4}{|c|}{ Reaction time (seconds) } \\
\cline { 2 - 5 } administration (hours) & Control & Zinc aspirin & Aspirin lysinate & Aspirin \\
\hline 1 & $6.83 \pm 0.47$ & $25.8^{* *} \pm 0.60$ & $14.8^{* *} \pm 0.47$ & $12.17^{* *} \pm 792$ \\
\hline 2 & $6.6 \pm 494$ & $14.0^{* *} \pm 0.51$ & $13.17^{* *} \pm 0.70$ & $11.67^{* * \pm 8.02}$ \\
\hline 3 & $7.0 \pm 0.57$ & $12.83^{* *} \pm 307$ & $11.33^{* *} \pm 494$ & $9.66^{*} \pm 494$ \\
\hline 4 & $7.0 \pm 0.36$ & $12.0^{* *} \pm 0.57$ & $10.33^{*} \pm 0.42$ & $8.667^{*} \pm 0.49$ \\
\hline 5 & $6.66 \pm 0.33$ & $9.17^{*} \pm 0.6$ & $8.62^{*} \pm 0.47$ & $8.02^{*} \pm 0.32$ \\
\hline
\end{tabular}

Values are mean of 6 experiments \pm standard errors.

* Significant difference $(\mathrm{P}<0.05)$ by (ANOVA) one way method compared with the control.

** Significant difference $(\mathrm{P}<0.01)$ by (ANOVA) one way method compared with the control.

Table 6: Analgesic activity of zinc aspirin, aspirin lysinate and aspirin as measured by hot plate method in mice.

\begin{tabular}{|c|c|c|c|c||}
\hline \multirow{2}{*}{$\begin{array}{c}\text { Time after oral } \\
\text { administration (hours) }\end{array}$} & \multicolumn{4}{|c|}{ Reaction time (seconds) } \\
\hline & Control & Zinc aspirin & Aspirin lysinate & Aspirin \\
\hline 1 & $6.8 \pm 0.48$ & $8.94^{*} \pm 0.15$ & $8.32^{*} \pm 0.21$ & $8.24^{*} \pm 0.42$ \\
\hline 2 & $6.2 \pm 0.2$ & $17.6^{* *} \pm 0.11$ & $16.7^{* *} \pm 0.18$ & $15.2^{* * \pm 0.32}$ \\
\hline 3 & $6.6 \pm 0.42$ & $15.6^{* *} \pm 0.15$ & $15.5^{* *} \pm 0.16$ & $13.6^{* *} \pm 0.23$ \\
\hline 4 & $6.5 \pm 0.38$ & $11.7^{* * \pm 0.17}$ & $10.2^{*} \pm 0.22$ & $7.9^{*} \pm 0.46$ \\
\hline 5 & $7 \pm 0.38$ & $8.4^{* * \pm 0.35}$ & $8.1^{*} \pm 0.23$ & $7.3 \pm 0.27$ \\
\hline
\end{tabular}

Values are mean of 6 experiments \pm standard errors.

* Significant difference $(\mathrm{P}<0.05)$ by (ANOVA) one way method compared with the control.

** Significant difference $(\mathrm{P}<0.01)$ by (ANOVA) one way method compared with the control.

Table 7: Analgesic activity of zinc aspirin, compared with aspirin lysinate and aspirin against pbenzoquinone induced writhing in mice.

\begin{tabular}{||l|c|c|c|c|c|}
\hline \multicolumn{1}{|c|}{ Drugs } & \multicolumn{5}{c|}{ Time after rectal administration (hours) } \\
\hline & 1 & 2 & 3 & 4 & 5 \\
\hline Control & 0 & 0 & 0 & 0 & 0 \\
\hline Zinc aspirin & 90 & 80 & 60 & 30 & 10 \\
\hline Aspirin lysinate & 80 & 70 & 60 & 20 & 10 \\
\hline Aspirin & 70 & 50 & 40 & 10 & 10 \\
\hline
\end{tabular}

- Data represent the percentage protection against p-benzoquinone induced writhing.

- Groups of 10 mice were used for each tested time interval.

Table 8: Analgesic activity of zinc aspirin, compared with aspirin lysinate and aspirin against pbenzoquinone induced writhing in mice.

\begin{tabular}{|l|c|c|c|c|c|}
\hline \multicolumn{1}{|c|}{ Drugs } & \multicolumn{5}{c|}{ Time after oral administration (hours) } \\
\hline & 1 & 2 & 3 & 4 & 5 \\
\hline Control & 0 & 0 & 0 & 0 & 0 \\
\hline Zinc Aspirin & 70 & 80 & 70 & 60 & 20 \\
\hline Aspirin lysinate & 60 & 70 & 60 & 50 & 10 \\
\hline Aspirin & 40 & 60 & 50 & 40 & 10 \\
\hline
\end{tabular}

- Data represent the percentage protection against p-benzoquinone induced writhing.

- Groups of 10 mice were used for each tested time interval. 


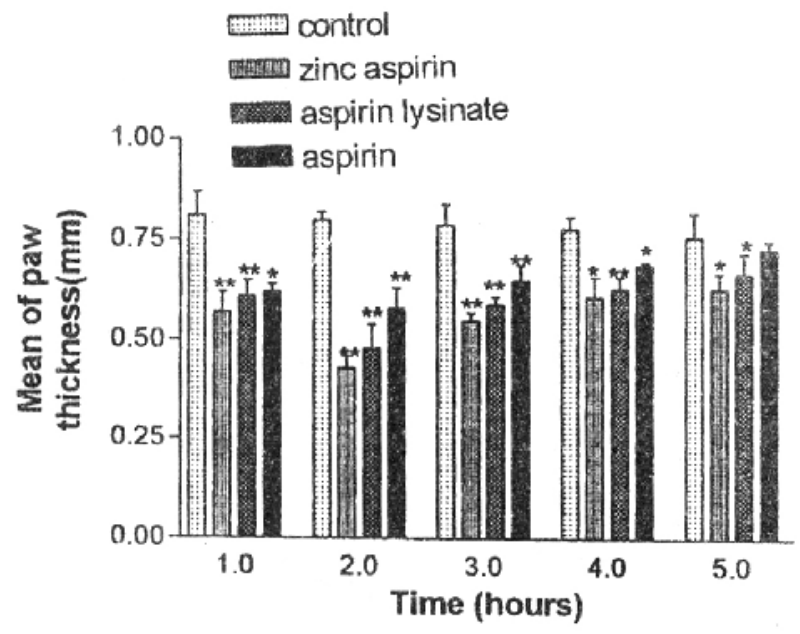

Fig. 4: Time following oral administration antiinflammatory activity of zinc aspirin, aspirin lysinate, and aspirin after $1 \mathrm{~h}, 2 \mathrm{~h}, 3 \mathrm{~h}$, $4 \mathrm{~h}$ and 5 hours of oral administration against inflammation induced by carageenan in rats.

Values are mean of 6 experiments \pm S.E.

* Significant difference from control values at $\mathrm{P}<0.05$

** Significant difference from control values at $\mathrm{P}<0.01$.

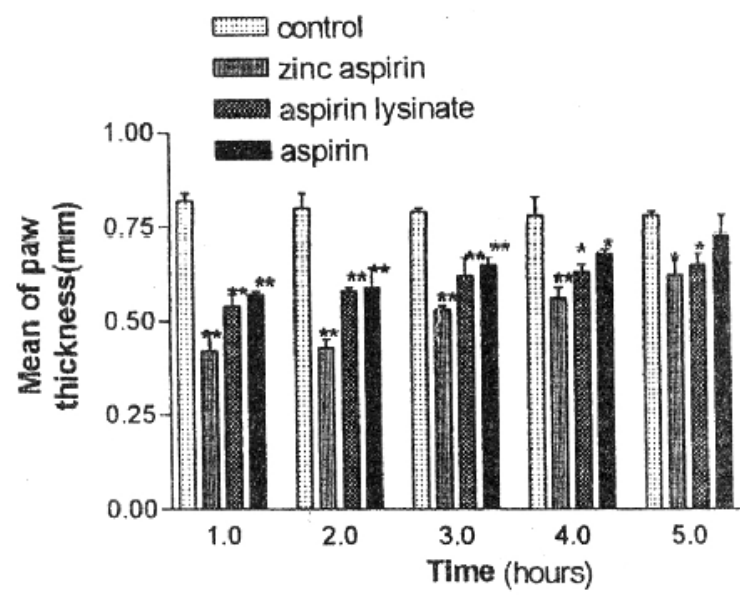

Fig. 5: Time following rectal administration antiinflammatory activity of zinc aspirin, aspirin lysinate, and aspirin after $1 \mathrm{~h}, 2 \mathrm{~h}, 3 \mathrm{~h}$, $4 \mathrm{~h}$ and 5 hours of rectal administration against inflammation induced by carageenan in rats.

Values are mean of 6 experiments \pm S.E.

* Significant difference from control values at $\mathrm{P}<0.05$

** Significant difference from control values at $\mathrm{P}<0.01$.
Results of the present study revealed that zinc aspirin possessed pronounced antiinflammatory properties. These results are similar to those obtained by Anil and Hardeep, ${ }^{41}$ who reported rat hind paw oedema induced by carrageenan has been markedly inhibited by zinc aspirin. The greater antiinflammatory effect of zinc aspirin can be attributed to the inhibition of prostaglandin biosynthesis by aspirin as well as by zinc, ${ }^{44}$ plus the anti-inflammatory action of zinc medicated through impairment of the phagocytic capacity of macrophages and increase in the viability, ${ }^{51}$ interference with the complement system, $^{52}$ and stabilization of lysosomal membrane as measured by the release of B-glucuronidase-probably through an inhibitory effect of zinc on lipid per- oxidation and stimulation of superoxide dismutase which play a key role in the protection of tissues against toxic effects of anions. ${ }^{53,54}$

\section{CONCLUSION}

The prepared zinc aspirin suppositories showed acceptable physicochemical characteristics (hardness, melting range and drug content). The release of aspirin from zinc aspirin suppositories was higher than aspirin suppositories. The release of aspirin from zinc aspirin suppositories followed Fickian/diffusion transport mechanism.

The oral administration and prepared suppositories of zinc aspirin exhibited greater anti-inflammatory and analgesic activity as compared to aspirin lysinate or aspirin. The bioavailability of zinc aspirin was significantly $(\mathrm{P}<0.05)$ higher than that of aspirin lysinate and aspirin. To our knowledge this is the first study carried out to investigate the pharmacokinetics and pharmacodynamic of zinc aspirin administered rectally.

Based on the results obtained in this study, the authors recommend the use of zinc aspirin for the preparation of rectal suppositories using suppocire AM as a base. This would eliminate the undesirable side effects (rectal irritation and discomfort) and increase the bioavailability of aspirin. 


\section{REFERENCES}

1- J. R. Leonards and G. Levy, J. Pharm. Sci., 59, 1511-1513 (1970).

2- C. H. Morris, J. E. Christian and W. G. Hansen, J. Pharm. Sci., 60, 790-791 (1971).

3- R. T. Schoen and R. J. Vender, Am. J. Med., 86, 449-758 (1989).

4- Martindale, The Extra Pharmacopoeia, 31 ed., Royal pharmaceutical Society, London, Aspirin, pp. 17 (1996).

5- P. M. Fraser, R. Doll, M. J. S Langman, J. J. Misieewicz and H. H. Shawdon, Gut, 13, 459-463 (1972).

6- D. J. Frommer, Med. J. Aust., 2, 793-796 (1975).

7- C. H. Cho, C. W. Ogle and S. Dai, Pharmacology, 17, 32-38 (1968).

8- C. H. Cho and C. W. Ogle, Eur. J. Pharmacol., 48, 97-105 (1978a).

9- C. H. Cho and C. W. Ogle, Experintia, 34, 90 (1978b).

10- C. W. Ogle and C. H. Cho, Pharmacol. Res. Commin., 9, 679-688 (1977).

11- S. H. Wong, C. H. Cho and C. W. Ogle, Pharmacology, 33, 94-102 (1986).

12- M.L. Kong, Effects of zinc sulphate on acetic acid-induced gastric ulceration, J. pharm. Pharmacol., 42; 657-659 (1990).

13- O. J. Clemmensen, J. Siggard-Anderson, A. M. Worm, D. Stahl, F. Frosr and I. Bloch, Br. J. Dermatol., 103, 411-415 (1980).

14- A. K. Singla and H. Wadhwa, Int. J. Pharm., 108, 173-185 (1994).

15- Y. P. Jiang, S. C. Wu, Y. B. Chen and Y. Li, Chin. Pharm. J. Zhongguo. Yaoxue Zazhi, 30, 152-155 (1995).

16- S. J. Carter, Copper and Gunn's, In Dispensing for Pharmaceutical Students, Pitman Medical Ltd., London, p. 238 (1976).

17- A. R. Fasshi, R. Dowse and S. Daya, Drug Dev. Ind. Pharm., 15, 235-251 (1989).

18- USP23, NF18, Aspirin Suppositories, p. 134 (1995).

19- R. D. Kirchhoefer, E. Jefferson and P. E. Flinn, J. pharm. Sci., 71, 1049-1052 (1982).

20- A. Abd-Elbary and C. W. Whitworth, J. Pharm. Sci, 16, 49-52. B.P., Volume III, Aspirin, p. 752 (1981).
21- E. A. Fouad and F. A. Mohammad, Bull. Pharm. Sci., Assiut Univ., 23, 23-30 (2000).

22- P. L Ritger and N. A. Peppas, J. Controlled Release, 5, 37-42 (1987).

23- P. K. Puranik, N. C. Manekar and A. K. Dorle, J. Micro-encapsulation, 9, 425-435 (1992).

24- O. A. Al-Swayeh, R. H. Clifford, P. Del Sol dato and P. K. Moore, British Journal of Pharmacology, 129, 343-350 (2000).

25- W. D. Mason and R. Gillilan, Anal. Letter, 16, 903-912 (1983).

26- S. Niazi, in "Textbook of Biopharmaceutics and Clinical Pharmacokinetics, Appleton-CenturyCrofts, New York, p. 151 (1992).

27- L. Shargel and B. C. Andrew, in Applied Biopharmaceutics and Pharmaceutics, $3^{\text {rd }}$ Ed., Prentice-Hall International Co., Appleton \& Lange, London, p. 174 (1993).

28- A. J. Lewis and G. F. Gebhart, Brain Research, 124, 283-303 (1977).

29- R. Okun, S. C. Liddon and L. Lasagna, J. Pharmacol. Exp. Then., 139, 107-113 (1963).

30- C. Winter, E. Risley and G. W. Nuss, Proc. Soc. Exp. Biol. Med., 3, 544. (1962).

31- U. Hartmann, H. Vahrenkamp, Bull. Pol. Acad. Sci. Chem., 42, 161-167 (1994), Through Chem. Abst., 122, 280692.

32- J. N. Lambi, A. T. Nsehyuka, N. Egbewatt, L. F. R. Cafferata, A. Jarvia, Thermochimica Acta., 398 (1-2), 145-151 (2003).

33- A. F. Reza and W. A. Ritschel, J. Pharm. Sci. 82, 750-754 (1993).

34- E. L. Parrott., J. Pharm. Sci. 60, 867-872 (1971).

35- P. R. Motgomery and D. S. Sitar, Biopharmaceutics and Drug Disposition., 7, 21-25 (1986).

36- F. M. Williams, Clinical Pharmacokinetics, 10, 392-403 (1985).

37- J. Ewoud, Hoogdalem Van, A. G. DeBoer and D. D., Clinc. Pharmaco., 21, (2) 110128 (1991).

38- M. Rowland, S. Riegelman, P. A. Harris and S. D. Shalkaff, J. Pharm. Sci. 61, 379385 (1972). 
39- A. K. Pedersen, G. A. Fitzgerald, New England Journal of Medicine, 311, 12061211 (1984).

40- D. D. Breimer, Yakuzaigaku., 48, 75-85, (1988).

41- K. S. Anil and W. Hardeep, International Journal of Pharmaceutics, 108, 173-185 (1994).

42- J. R. Vane, Nat. New Biol., 231, 232-235 (1971).

43- S. Moncada, S. H. Ferreira and J. R. Vane, Nature, 246, 217-219. (1973).

44- D. H. Nugteren, R. K. Beerthuis and D. A. Van Dorp, Recueil., 85, 405-411 (1966).

45- J. R. Vane, J. A. Mitchell, I. Appleton, A. Tomlinson, D. Bishop-Bahey, I. J. Croxtal and D. A. Whloughby, Proc. Natl. Acad. Sci., USA, 9, 2046-2050 (1994).

46- E. A. Meade, W. L. Smith and D. L. Dewitt, J. Biol. Chem., 268, 6610-6614 (1993).

47- M. Dirosa, J. P. Giroud and D. A. Willoughby, J. Pathol., 104, 15-29. (1971).
48- K. Seibert, Y. Zhang, K. Leahy, S. Hauser, J. Masferer, W. Perkins, L. Lee and P. Isakson, Proc. Natl. Acad. Sci., USA, 91, 12013-12017 (1994).

49- N. K. Bauchton-Smith, A. M. Deakin, R. L. Follenfant, B. J. Whittle and L. G. Garland, Br. J. Pharmacol., 110, 896-9-2 (1993).

50- J. C. Fantone and P. A. Word, Am. J. Pathol., 107, 397-418 (1982).

51- L. Karl, M. Chvapil and C. F. Zakoski, Proc. Soc. Exp Biol. Med., 142, 11231127 (1973).

52- K. Yamamoto and M. Takanashi, Int. Arch. Allergy Appl. Immun., 48, 653-663 (1975).

53- M. Chavapil, Life Sci., 13, 1041-1049 (1973).

54- T. Yoshikawa, H. Tanaka, M. Kondo, Biochem. Med., 33, 320-326 (1985). 